\title{
Male reproductive patterns in nonhibernating bats
}

\author{
P. H. Krutzsch \\ Department of Anatomy, College of Medicine, University of Arizona, \\ Tucson, Arizona 85724, U.S.A.
}

\begin{abstract}
Summary. Knowledge relative to the reproduction of nonhibernating bats is reviewed. Events in the male, as they are now understood, are summarized for all families for which data exist. Attention is given to the wide species diversity of male accessory sex organs in respect to gross structure and glandular complement. Stability or variability of organization of the male reproductive system is noted. Functional relationships between primary and accessory sex organs are considered and any synchrony between these organs and their functional cyclicity identified.

Various frequencies of male reproductive cycles are examined for each species within families. Factors influencing male reproductive events in nonhibernating Chiroptera are briefly considered. It has long been speculation that reproductive cycles under natural conditions are strikingly related to the environment, with such features as temperature, moisture, length of day and available food all implicated. These cues, however, appear to be filtered through varied genetic potential and physiological patterns, since not all species respond similarly, even though residing together in a homogeneous environment. Variations between certain species in frequency and length of the oestrous cycle seem to be accommodated to by parallel adjustments in the male, including extended sperm production or storage and continued secretory activity of accessory sex glands.
\end{abstract}

\section{Introduction}

For the purpose of this review, nonhibernating bats are defined as either physiologically incapable of undergoing sustained hibernation or normally confined to geographical regions wherein the environment does not elicit torpor or sustained hibernation.

Nonhibernating bats (Gopalakrishna, 1948; Wimsatt \& Trapido, 1952; Vamburkar, 1958; Mutere, 1968a, b; Dwyer, 1970; Wilson \& Findley, 1970; Fleming, Hooper \& Wilson, 1972; Medway, 1972; Wilson, 1973; Krutzsch, Watson \& Lox, 1976; Myers, 1977), display a variety of reproductive patterns even though environmental cues often seem subtle and seasonality is poorly marked. Fleming et al. (1972) and Wilson (1973), utilizing the distinct and different female reproductive patterns of neotropical bats, arranged their breeding cycles into four broad categories ("aseasonal polyoestry", "seasonal polyoestry", "bimodal polyoestry" and "seasonal monoestry"). If one examines the available literature describing the reproductive cycles of the Old World nonhibernators, the above categories each appear to have their Old World counterparts.

Although the interrelations that exist between segments of the male and female reproductive processes are poorly known, it certainly must be true that not all sexual behaviour is initiated by the female solely as the result of onset of oestrus (heat). It is known, for example, that there are well marked structural secondary sexual characteristics in the males of a number of nonhibernating species. Secondary sexual characteristics appear to serve as indicators of mating readiness by providing various visual, auditory and/or olfactory stimuli in announcing sexual readiness, marking the mating territory and inducing receptive females to mate. The function of these specialized morphological characteristics is probably under the control of testicular 
androgens since they exhibit seasonal changes in keeping with other normal male reproductive tract changes.

Since early in this century, there has been great emphasis on the study of the reproductive system and its processes in mammals. Nevertheless, only fragmentary information has accumulated concerning the male reproductive biology of nonhibernating Old or New World Chiroptera and rarely has a repertoire of analytical tools common to current basic biological investigation been employed. However, even though published findings are not in great detail, they serve, in conjunction with observational data, to provide some knowledge of the basic patterns of male reproductive processes. Further information has been obtained by observation of the more conspicuous female events. In most instances nonhibernating bats demonstrate reasonable synchrony between male and female reproductive processes. Spermatozoa are most often produced and accessory sex glands are secretorily active at a time consistent with the onset of the oestrous cycle in the female and copulation, ovulation and fertilization are usually contemporary events. There are exceptions (Gopalakrishna \& Madhavan, 1971; Racey, Suzuki \& Medway, 1975; Myers, 1977) wherein spermatozoa are stored in the uteri of nonhibernating species much the same as in hibernating Myotis lucifugus (Wimsatt, Krutzsch \& Napolitano, 1966).

The reproductive system of males of species in which the females are polyoestrous demonstrates gonadal and accessory sex gland synchrony, but it is not clear whether all individuals are reproductively active throughout the year. The constant small size and nonsecretory appearance of the interstitial cells in the testes of Artibeus jamaicensis (Tamsitt \& Mejia, 1962) and $A$. lituratus (Tamsitt \& Valdivieso, 1965) show little morphological correlation with the reproductive status of the bat, suggesting that there is continuous steroid release. On the other hand, in seasonally monoestrous species sexual synchrony of individuals throughout the entire population is likely.

Other species demonstrate special peculiarities in their sex cycle. Miniopterus australis concludes gametogenesis in July and the testes involute but spermatozoa remain stored in the epididymides for several weeks until the females are receptive to insemination (Richardson, 1977). It is possible that this delay in ejaculation permits the spermatozoa to undergo capacitation or some other physiological preparative process essential for successful fertilization. Tylonycteris pachypus and T. robustula (Medway, 1972) also undergo early testicular regression with sperm storage in the epididymides until copulation. In Rhinopoma kinneari the testes are always abdominal and spermatogenesis occurs during an apparent inactive physiological (torpor?) period (Kumar, 1965). Although Rhinopoma is seasonally monoestrous, spermatozoa are retained by the male in the epididymides and ampullary glands throughout the year.

The male accessory sex organs show great plasticity in form and species distribution. These glands (prostate, seminal vesicle, ampullary, urethral and Cowper's) contribute various substances (fructose, citric acid, sialic acid and zinc) to the ejaculate (Rajalakshmi \& Prasad, 1970; Krutzsch et al., 1976; Mokkapati \& Dominic, 1976). It is presumed, although not experimentally demonstrated, that accessory sex gland secretions in certain species of nonhibernators (rhinolophids, vespertilionids and megadermatids) produce, in conjunction with uterine secretions, the vaginal plug found in recently inseminated females (Matthews, 1941). Whatever additional functions might be ascribed to accessory gland secretions it is clear that in seasonal species (monoestrous and bimodally polyoestrous) these organs hypertrophy and/or involute in direct synchrony with the testicular cycle. However, in those species breeding throughout the year (aseasonally polyoestrous) or virtually continuously (seasonally polyoestrous) in which the reproductive processes are interrupted only for a brief period of sexual inactivity, accessory sex glands may remain secretory, testes functional and epididymides spermfilled. This impression, gained from apparent year-round reproductive activity, may actually be misleading since there have been no studies performed to determine whether males remain continuously reproductively active throughout the year. 
Varieties of arrangements, variation in the specific accessory sex glands present, their location with respect to other reproductive organs, and variation in their histological organization demonstrate diversity of the male reproductive system. The combined secretory effect of the accessory sex glands is to provide seminal plasma and species differences in organ complement presumably reflect physiological requirements.

The details of reproductive cycles disclose the wide-ranging variation in reproductive schemes that exists within closely related genetic groups even though the different species reside in nearly ecologically and geographically identical sites. The influence of environmental factors, though not usually predictable, is nevertheless apparently important. Clearly temperate hibernating insectivorous species are limited to seasonal monoestrous behaviour by environmental factors primarily related to metabolic processes (see Racey \& Tam, 1974). Equally apparent in the nonhibernating species is the easing of environmental constraints on demanding metabolic processes such as pregnancy. This is reflected in the widespread establishment of aseasonal and polyoestrous reproductive patterns in conjunction with increased variability of food habits and a broadening of the diet from purely insectivorous to include frugivorous, haemophagous, carnivorous, ichthyophagous and nectivorous habits.

\section{Observations}

The families considered in this review are the Pteropodidae, Rhinopomatidae, Emballonuridae, Nycteridae, Megadermatidae, Rhinolophidae (including Hipposideridae), Phyllostomatidae (including Desmodontidae), Natalidae, Vespertilionidae and Molossidae: insufficient data are available for other families.

\section{Pteropodidae}

These bats are restricted to the tropics and subtropics of the Old World from Africa to southeast Asia, Australia, Samoa and the Carolines (Koopman \& Jones, 1970). The male reproductive tract of pteropodids shows relatively little variation in its gross organization. The basic design (Text-fig. 1c) consists of paired testes (which seasonally or daily move via the inguinal canal from an intra-abdominal to a scrotal position) and a series of accessory sex glands: seminal vesicles, prostate and Cowper's glands. The microscopic appearance of the accessory sex glands varies seasonally; reproductively active individuals have hypertrophied, secretion-filled glands (Pl. 1, Fig. 1) whereas in sexually quiescent males the glands are small and empty.

Male reproductive activity can be arranged into three basic schemes each in phase with the terms applied to the female reproductive (oestrous) cycle although it is recognized that the terms are technically inapplicable to males.

Aseasonally 'polyoestrous'. Throughout the population males show continuous testicular spermatogenesis and accessory gland hypertrophy but it is not clear whether all or only some individuals are continuously reproductively active. The following species are described as undergoing year-round reproduction: Eonycteris spelaea (Beck \& Lim, 1973), Stenonycteris lanosus, Myonycteris torquata wroughtonia, Epomophorus labiatus, Epomops franqueti, Micropteropus pusillus (Kingdon, 1974; Okia, 1974a, b), Rousettus aegyptiacus (Mutere, 1968a), and Cynopterus brachyotis (Lim, 1970).

Bimodally seasonally 'polyoestrous'. Males may have some spermatozoa in the testis and epididymis year-round but, like the females, are considered to demonstrate two breeding peaks, as shown by bimodal peaks in testicular weight and size and in the presence of epididymal spermatozoa. The following species demonstrate at least two reproductive cycles but all may be continuous breeders: Rousettus aegyptiacus (Mutere, 1968a, b), R. leschenaulti (Gopalakrishna, 1969), Epomophorus anurus (Okia, 1974b) and Micropteropus pusillus (Jones, 1972). 
Aseasonally 'monoestrous'. Males may have spermatozoa in the testes and epididymides for several months but exhibit only a single breeding period after which their reproductive organs involute and spermatozoa are lost. These species have been described as monoestrous breeders: Pteropus geddei, P. eotinus (Baker \& Baker, 1936; Groome, 1940), P. g. giganteus (Marshall, 1947; Moghe, 1952), P. poliocephalus, P. gouldi, P. scapulatus (Nelson, 1965), P. comorensis, $P$. voeltzkowi (Kingdon, 1974), Eidolon helvum (Mutere, 1965, 1967, 1968b; Jones, 1972; Kingdon, 1974; Fayenuwo \& Halstead, 1974).

\section{Family Rhinopomatidae}

The mouse-tailed bats occur from North Africa east through southern Asia to Sumatra (Koopman \& Jones, 1970). Paired testes which lie permanently within the abdomen (Text-fig. la) produce spermatozoa during a period when males undergo reduced metabolism. Spermatozoa are then retained in the ampullary glands and epididymides throughout the year even though testes and accessory glands are involuted from April onward. Breeding is monoestrous and seasonal in March.

\section{Family Emballonuridae}

The sac-winged and sheath-tailed bats occur from northern Mexico to southern Brazil in the New World, in the Near East, south to southern parts of Africa and Australia and on Pacific islands east to Samoa, in the Old World (Koopman \& Jones, 1970).

The male reproductive tract has either the ampullary or seminal vesicles missing (Text-fig. 1b). Reproductively active bats have hypertrophied, secretion-filled glands, but in sexually quiescent males the glands are involuted (Pl. 1, Fig. 2). Emballonurids show at least aseasonal polyoestrous and seasonal monoestrous breeding patterns.

Seasonally 'monoestrous'. In Taphozous georgianus from Western Australia, males demonstrate continuous spermatogenesis and spermatozoa are present in the reproductive tract during most months (Kitchener, 1973). Testes vary in position: scrotal in summer and abdominal at other times. Taphozous nudiventris of India and Iraq (Basra, 1967) are also monoestrous although those of Iraq inseminate in the fall and these stored spermatozoa result in spring fertilization. Indian bats apparently do not become inactive during winter. Females ovulate and become fertilized in the spring. There is at least one neotropical species, Saccopteryx bilineata, described as being seasonally monoestrous (Wilson, 1973) but nothing has been published concerning the male cycle.

Aseasonally 'polyoestrous'. The male gametic cycle in Taphozous longimanus is continuous and breeding probably occurs year-round in view of the presence of pregnant females in all months of the year. The accessory organs and testes have only been described for one point in time (Gopalakrishna, 1955; Murthy, 1969).

\section{Family Nycteridae}

The slit-faced bats occur in Africa (except in the Sahara Region, Madagascar and Arabian coast), Malayan Peninsula, Sumatra, Java, Borneo and adjacent islands (Koopman \& Jones, 1970). The male reproductive tract of Nycteris consists of paired testes, ampullary, prostate and Cowper's glands. In N. luteola (Matthews, 1939) and N. hispida (Matthews, 1941) testes are thought to produce spermatozoa year-round and accessory glands are believed to be functional throughout the same period (no microscopic evidence is available). Both active and inactive testes occur in $N$. thebaica at the same time (Verschuren, 1957) but no reference is made to the age of the specimens; possibly those with inactive gonads were sub-adults. Females were found to be pregnant and lactating at one time and clearly are polyoestrous. With additional data more species will probably be placed in this category. 
PLATE 1
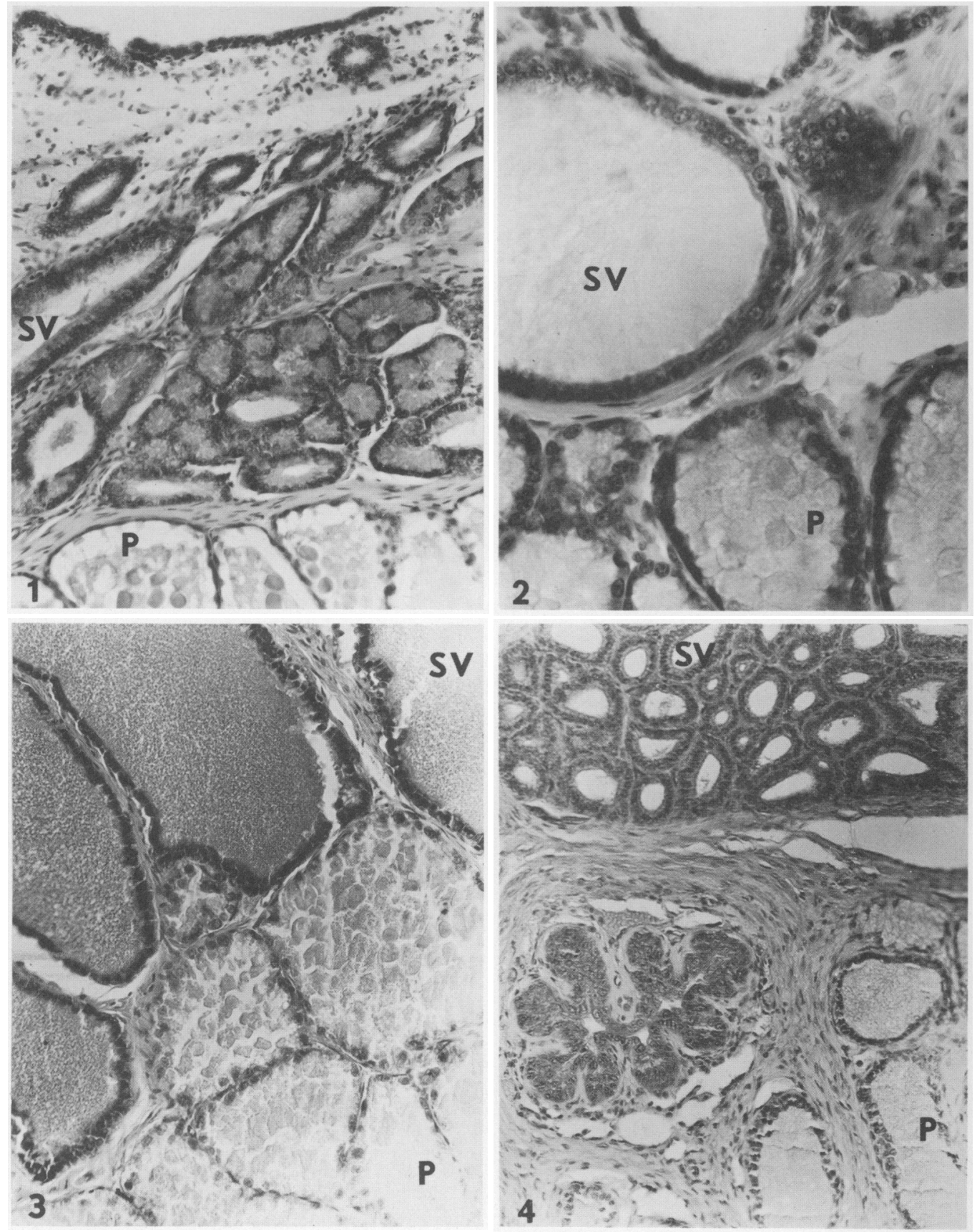

Fig. 1. Transverse section through the seminal vesicles (SV) and prostate (P) of Eonycteris spelaea. $\times 120$.

Fig. 2. Transverse section through the seminal vesicles (SV) and prostate (P) of Rhynchonycteris naso. $\times 290$.

Fig. 3. Transverse section through the seminal vesicles (SV) and prostate (P) of Desmodus rotundus. $\times 120$.

Fig. 4. Transverse section through the seminal vesicles (SV) and prostate (P) of Natalus stramineus. $\times 175$.

(Facing p. 336) 
(a)

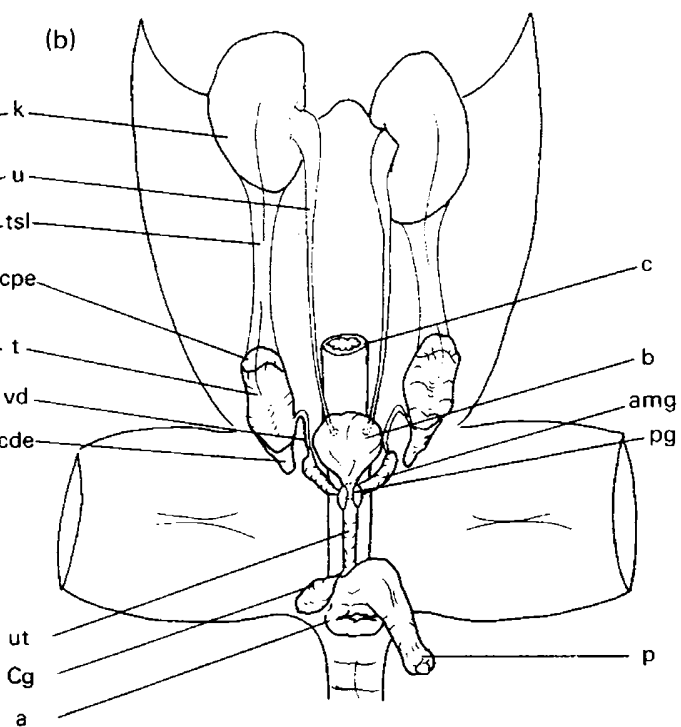

(c)

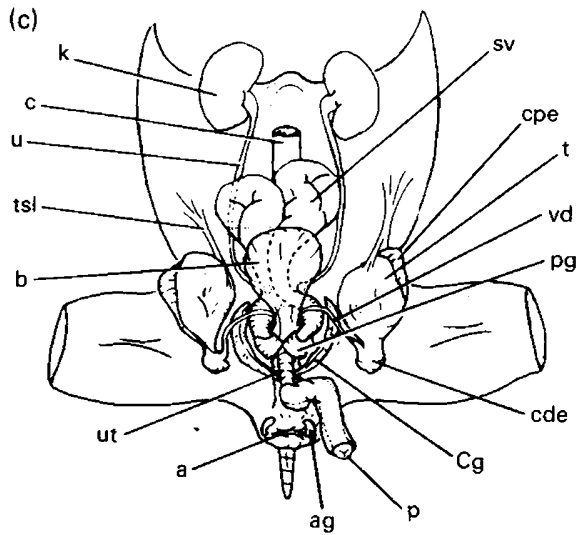

(e)

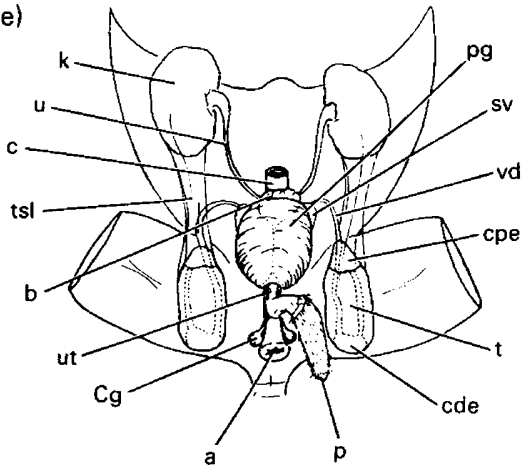

(d)
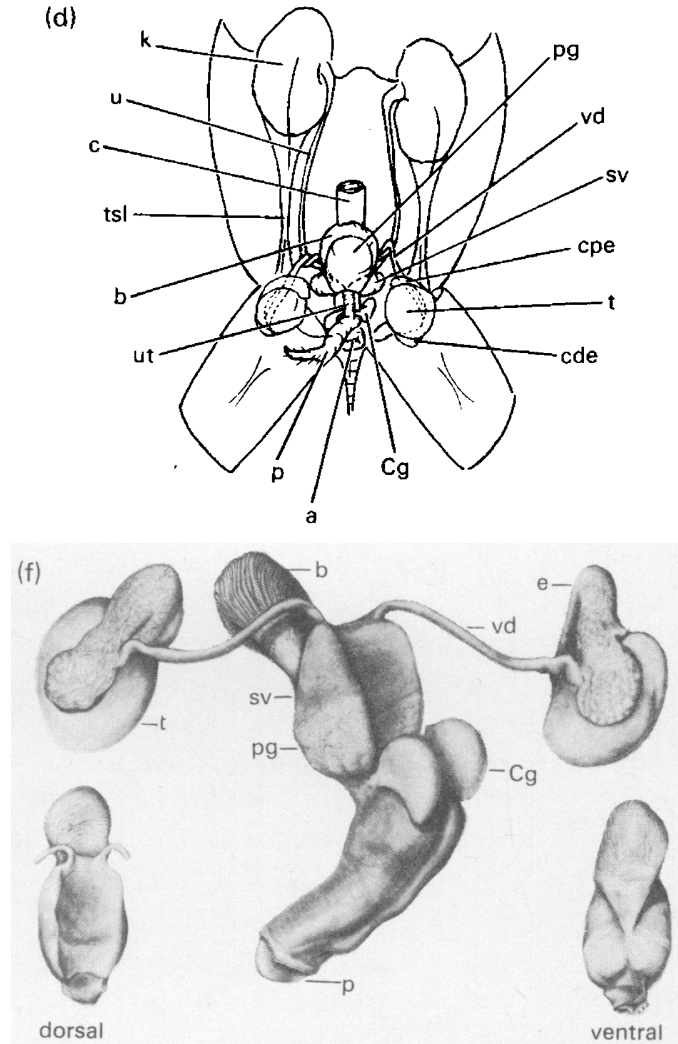

Text-fig. 1. Line drawings of the male reproductive tracts of (a) Rhinopoma kinneari (F. Rhinopomatidae); (b) Taphozous longimanus (F. Emballonuridae); (c) Eonycteris spelaea (F. Pteropodidae); (d) Natalus stramineus (F. Natalidae); (e) Molossus fortis (F. Molossidae); (f) Desmodus rotundus (F. Phyllostomatidae). a, anus; ag, anal gland; amg, ampullary gland; $b$, bladder; c, colon; $\mathrm{Cg}$, Cowper's gland; cpe, caput epididymidis; cde, cauda epididymidis; e, epididymis; k, kidney; p, penis; pg, prostate gland; s.v., seminal vesicle; t, testis; tsl, testicular suspensory ligament; u, ureter; ut, urethra; vd, vas deferens. 


\section{Family Megadermatidae}

The false vampire bats occur in central Africa, India, southeast Asia, Philippines, and East Indies to Australia (Koopman \& Jones, 1970).

The male reproductive tract consists of paired testes, either ampullary glands or seminal vesicles, prostate and Cowper's glands. The testicular cycle begins in July and is continuous until December. However, greatest testicular size and sperm productivity occur from October through November.

In India the seasonal monoestrous breeding cycle of megadermids is consumated by mating in December. The primary and accessory sex glands gradually involute until the resting state is reached in June. This cyclic pattern is characteristic for both Megaderma spasma and Megaderma [=Lyroderma] lyra (Ramakrishna, 1951; Ramaswamy, 1961).

Macroderma gigas from Australia is also a seasonally monoestrous species with cycles clearly varying according to the latitude. Females are pregnant in July-November in the arid southern parts of Western Australia, whereas they are pregnant from June to September in the more tropical northern regions of Western Australia. Males are apparently fertile well in advance of mating which occurs in May or June (Douglas, 1967).

\section{Family Rhinolophidae (including Hipposideridae)}

The horseshoe bats occur in the Old World from the British Isles and Africa east to Japan, Philippines, New Hebrides, and northern and eastern Australia (Koopman \& Jones, 1970).

There may be differences between various species in the complement of accessory glands. Ampullary or seminal vesicles or both are present; urethral glands are always found in Rhinolophus and often in Hipposideros; prostate and Cowper's glands are common to all species reported. Little has been published on nonhibernators with most available data concerning Hipposideros caffer (Matthews, 1941; Mutere, 1970; Menzies, 1973, Kingdon, 1974). This species is thought to be seasonally monoestrous throughout its range, with the testes smallest in July and largest in November. Brosset (1968) reported that $H$. caffer experiences two breeding cycles in Gabon, Africa, in respect to the equator, one occurring in March, related to the northern spring, and the other in October in conjunction with the southern spring. Menzies (1973) found that the weight of the testes was minimum in May and maximum in November and recorded that testes undergo spermatogenesis beginning in May and the seminiferous tubules and epididymides are sperm-filled in November. Spermatozoa are gone from the testes in December and only a few remain in the epididymides. Other rhinolophid species, Hipposideros commersoni, H. cyclops (Lang \& Chapin, 1917; Kingdon, 1974) and Triaenops afer (Matthews, 1941), are also considered to be seasonally monoestrous. Their testicular development is greatest in December and the testes are involuted in June-July. Menzies (1973) also ascribed seasonal monoestrous behaviour to Rhinolophus landeri; testes reaches maximum size in December and regressed to a minimum in July. The testicular spermatogenic cycle was followed by sperm storage in the epididymides. Spermatozoa were available and remained so for mating in $R$. landeri over a longer time than for Hipposideros caffer. Menzies (1973) speculated that females of $R$. landeri and $H$. caffer showed delayed implantation. However, the evidence was not conclusive.

\section{Family Phyllostomatidae (including Desmodontidae)}

The leaf-nosed and vampire bats occur in the New World (primarily tropical areas) from southwestern United States and Antilles south to northern Argentina and central Chile (Koopman \& Jones, 1970). 
The male reproductive tract shows little variation in its gross organization. The basic design (Text-fig. 1f) includes a multipartite accessory sex gland complex (ampullary, seminal vesicle and prostate) and Cowper's glands, the individual components of which are separated by fascial septa and connective tissue as seen microscopically (Pl. 1, Fig. 3). Grossly, the components are distinguished with difficulty: ampullary gland by vas deferens attachment; prostate by distal position and whitish colour; and seminal vesicle by its reddish colour. The microscopic and gross appearance of the accessory glands varies with the reproductive state.

Reproductive cycles in males can be separated into three basic patterns on the basis of the female oestrous cycles (Wilson, 1973).

Seasonally 'monoestrous'. The studies of Bradshaw (1961, 1962) and Krutzsch et al. (1976) have clearly demonstrated that the insectivorous Macrotus californicus has a single annual reproductive cycle. The male spermatogenic cycle is initiated in June; epididymal spermatozoa are available from August to December and copulation occurs in September-November. Testicular hypertrophy is accompanied by increased levels of testicular ascorbic acid and circulating plasma testosterone. Regression in testicular size begins in late September and testes are involuted by early December. Levels of testicular ascorbic acid and plasma testosterone decline at this time but detectable amounts of both are present year-round. The accessory sex gland cycle is synchronous with the testicular cycle. The accessory glands contain fructose, the concentration of which varies seasonally in direct response to testosterone. Only one other species, Pteronotus parnellii, has been demonstrated to exhibit seasonal monoestrous behaviour (Wilson, 1973).

Aseasonally 'polyoestrous'. The continuously repeated female breeding cycle with the resultant year-round reproduction in Desmodus rotundus was first described by Wimsatt \& Trapido (1952) who collected males in full sexual activity throughout the year in Panama and the Canal Zone. Their observations were substantiated by the occurrence of spermatogenesis and the presence of epididymal spermatozoa at all times. Since then others have confirmed these observations (Carter, 1970; Fleming et al., 1972; Wilson, 1973).

Bimodally 'polyoestrous'. Fleming et al. (1972) and Wilson (1973) suggest that many phyllostomatid species conform to this breeding scheme. Carter (1970) remarks that most phyllostomatids are polyoestrous. From data accumulating it would seem that two or more annual reproductive cycles is the dominant pattern.

The evidence concerning the male reproductive pattern is less abundant but the data, when available, suggest that males are capable of reproductive activity throughout the year. Tamsitt \& Valdivieso $(1963,1965)$, utilizing histological techniques on $A$. lituratus obtained over a 17 month period, concluded that males are capable of reproductive activity at any time of the year and that the male reproductive pattern is acyclic. They found no correlation between interstitial cell size or number and the reproductive condition. Cells were always small and few in number, a condition also described in Artibeus jamaicensis (Tamsitt \& Mejia, 1962). The true functional nature of these cells in Artibeus awaits steroid histochemical, electron microscopical, radioimmunoassay and receptor site analysis.

Tamsitt \& Mejia (1962) carried out microscopic observations on 6 adult male $A$. jamaicensis collected during a 1 -month period: 3 males were reproductively active and 3 inactive. Even though their sample was small and for a limited period, they suggested that A. jamaicensis exhibited acyclic breeding. Later support for this thesis was provided by Fleming et al. (1972) who measured testis length of $A$. jamaicensis collected over a 12-month period and concluded that testis size is maximal just before the time when females "are likely" to be sexually receptive and minimal when females are unreceptive, indicating an acyclic pattern. Their graph of testis length against time reveals that testis size does not appear to change significantly, thus lending support to the hypothesis of Tamsitt \& Mejia (1962).

Fleming et al. (1972) offer the same type of data for Uroderma bilobatum and Carollia perspicillata. Testes size, though varying somewhat annually, has been interpreted in the same way as for A.jamaicensis. 


\section{Family Natalidae}

The funnel-eared bats are found in the neotropics from northern Mexico and the Antilles south to Brazil (Koopman \& Jones, 1970).

The male reproductive tract consists of paired testes and a series of accessory sex glands (Text-fig. 1d). The microscopic appearance of the accessory glands varies seasonally; active individuals have hypertrophied glands (PI. 1, Fig. 4).

There are only two published accounts of male reproduction in Natalus stramineus from Mexico. Hall \& Dalquest (1963) reported small testes in January and Broadbooks (1961) gave testicular measurements from a December specimen. Specimens obtained from various northern hemisphere localities suggest that the spermatogenic cycle begins in late August-early September and spermatozoa continue to be present in the testes and epididymides until February-March. Accessory sex glands exhibit a similar cycle, hypertrophying in September and remaining enlarged and secretion-filled throughout the winter. Gradual involution occurs in January and February and the accessory glands are completely involuted by March. The male cycle conforms well with the apparent seasonally monoestrous reproductive pattern.

\section{Family Vespertilionidae}

The common bats have the broadest distribution of any living chiropteran family: north to the Arctic Circle in Palearctic and Nearctic regions, south to the southern parts of Africa, Australia and South America, and on many islands including Hawaii, Iceland and New Zealand (Koopman \& Jones, 1970).

The morphology of the male reproductive tract of the vespertilionids is exceedingly variable. The shape, size and number of the individual components of the accessory sex glands often differ dramatically between genera. Glands may be doubly paired, paired or single, and one or another (urethral, seminal vesicle or ampullary) may be lacking.

Reproductive activity in males can be separated into basic patterns which are in phase with similar periodicity expressed by the females (Wilson, 1973).

Seasonally 'monoestrous'. There are a number of nonhibernating vespertilionids that exhibit a single annual reproductive cycle. These species are usually found in regions where winter temperatures are mild or the year-round variation in seasonality of the environment (moisture, temperature, length of day) is greatly reduced. There is no standard reproductive mode, but there is an annual sexual rhythm which is usually in near synchrony with the female reproductive events. In those species studied to date, Lasiurus ega Paraguay: Myers, 1977); Scotophilus wroughtoni (India: Gopalakrishna, 1948); Tylonycteris pachypus and T. robustula (West Malaysia: Medway, 1972); Miniopterus australis (New Hebrides: Baker \& Bird, 1936; East Malaysia: Medway, 1971; Australia: Richardson, 1977), the male cycle (although possessing unique species variations) in general demonstrates that testicular hypertrophy, gametogenesis and epididymal enlargement are closely related to and probably direct the nearly simultaneous hypertrophy and secretory cycle of the accessory sex glands. These male changes usually occur close to female oestrus. Sperm storage in the female oviducts of $T$. robustula and $T$. pachypus in West Malaysia (Racey et al., 1975) and in the uterus and oviducts of Pipistrellus ceylonicus (Gopalakrishna \& Madhavan, 1971) are thought to ensure successful fertilization when oestrus is less synchronized.

'Polyoestrous'. Species have been described that may cycle two or three times annually. However, within those populations that produce two or more litters, there seems to be a decline of productivity (Myers, 1977) and a tendency towards less synchronized parturition peaks (Wilson \& Findley, 1970) as the year progresses, with total reproductive abstinence for a period resulting in fewer young produced at times less favourable for food production.

The species studied to date that have been defined as polyoestrous include examples from both the Old and New World: Myotis adversus (Australia: Dwyer, 1970), M. nigricans 
(Paraguay: Myers, 1977; Panama Canal Zone: Wilson \& Findley, 1970); M. albescens (Paraguay: Myers, 1977) and Eptesicus furinalis (Paraguay: Myers, 1977). Although all of these species are similar in that they undergo more than one reproductive cycle each year, they otherwise have relatively unique and personalized reproduction schemes.

Myotis adversus demonstrates two male reproductive peaks in which testes and epididymides are enlarged and active. These peaks occur from mid-March to June and again from October through November with testicular and epididymal size being reduced in between. Dwyer (1970) noted that the breeding season is longer in more tropical Australian latitudes and suggests that 3 litters in succession may occur at these lower latitudes.

Myotis nigricans breeds continually in Panama during most of the year but becomes reproductively quiescent for approximately 3 months in the late rainy season. Males show little variation in testicular size; however, most demonstrate all stages of gametogenesis throughout the active reproductive period. The epididymides contain spermatozoa in all adults but are not visibly distended. Testes involute during the dry season (September-November) and reproduction then ceases. Wilson \& Findley (1971) remarked on the geographic variation in the reproductive cycle of $M$. nigricans suggesting that in Mexico the testes of this bat were more like those of a temperate species. Myotis nigricans in Paraguay breeds two or three times yearly but does not experience a post-partum oestrus. Myers suggests that this bat has a low level (frequency) of breeding throughout the year. The male, as in Panama, is nearly aseasonal in its testicular cycle; however, the accessory glands change seasonally although Myers does not think that these changes are necessarily functionally significant. Myotis nigricans appears to have accommodated to living in a less seasonal tropical environment and thus its reproductive pattern differs from that of the Myotis of the temperate zones.

Myotis albescens, in Paraguay, breeds two or three times annually. Spermatogenesis occurs in autumn, winter and spring and spermatozoa are present in the epididymides in these seasons. The accessory glands are cyclic and are enlarged when interstitial cells appear (secretorily) active. Breeding halts during autumn and winter but bats do not hibernate.

Eptesicus furinalis, in Paraguay, breeds twice annually. There are two peaks of testicular activity. Testes undergo hypertrophy and gametogenesis during the autumn and reach a peak in early winter when the epididymides are swollen with spermatozoa. Involution occurs in late winter and no spermatozoa are present in the epididymides. Testes redevelop in the spring. The accessory glands are enlarged and secretory when interstitial cells appear to be most active.

\section{Family Molossidae}

The free-tailed bats occur in the Old World from southern parts of Europe and Asia south to Africa (except Sahara), East Indies, Australia and the Fiji Islands and in the New World from southwestern Canada through middle America and the Antilles to South America (Argentina and Chile) (Koopman \& Jones, 1970).

The male reproductive tract of molossids demonstrates strong homogeneity in form and glandular organization (Text-fig. 1e). Only normal changes in overall size in keeping with the general dimensions of the specimen involved are seen. Reproductive activity in males assumes one or another of two basic patterns in phase with the periodicity expressed by the female.

Seasonally 'monoestrous'. The studies of Mutere (1973a) on the reproduction of Otomops martiensseni at latitudes $1^{\circ} 5^{\prime} \mathrm{S}$ and $2^{\circ} 30^{\prime} \mathrm{S}$ have clearly demonstrated that this tropical insectivorous molossid has a single annual breeding cycle. The testes hypertrophy and attain their greatest mean weight in August when copulation follows. Pregnancy is apparently initiated in October and continued until January. The testes gradually involute and reach their minimum weight in December. The testes remain inactive until redevelopment begins in June and July. This is the only published account of the reproductive cycle of a monoestrous nonhibernating, tropical molossid. 
Seasonally bimodally 'polyoestrous'. There are a number of nonhibernating molossids that are described as undergoing two annual breeding cycles. Male Tadarida midas, an East African species, have enlarged testes in June and March, whereas females give birth in February or September (Kingdon, 1974). Other molossids, Tadarida congica, T. namula, T. condylura and $T$. thersites, are all reported to have two breeding cycles per year (Kingdon, 1974). Braestrup (1933) described two breeding cycles in Chaerephon with embryos in January-March and August-September. The testes of Tadarida condylura, however, show little seasonal weight change and are sometimes scrotal but are still capable of inseminations because females are pregnant in May, June and July and then again in December, January and February, suggesting mating in April and November.

Aseasonally 'polyoestrous'. Marshall \& Corbet (1959) have reviewed the breeding biology of Tadarida [= Chaerephon] hindei. They found that this species experiences two reproductive peaks annually although substantial reproduction (up to $37 \%$ pregnancy) occurs in every month of the year. Marshall \& Corbet pointed out that individuals (as distinct from populations) of $T$. hindei do not reproduce continuously. They observed that in some adult males one or both testes were intra-abdominal and when both were retracted spermatogenesis had ceased. Nevertheless, most adult males possessed spermatozoa in their epididymides throughout the year and appeared capable of fertilization. This species is an excellent example of the vigorous reproduction that can occur even with an aseasonally polyoestrous pattern. Marshall \& Corbet apparently placed great emphasis on the peaks in pregnancy in describing this reproductive population as bimodal. However, they did point out the general pattern of continuous reproduction. Mutere (1973b) described the reproductive cycle of Tadarida pumila [ = Tadarida hindei], clearly defining this species as presenting a continuous breeding cycle. It was shown that testes expressed no seasonal variation in sperm production. Testes were noted as more fully descended into the scrotum at times but the significance of this observation is obscure unless it relates to the reduced spermatogenesis observed when testes are intra-abdominal. Harrison (1958) reported that in Nigeria on 18 May an adult female $T$. pumila was obtained that was pregnant and lactating, and had therefore experienced two pregnancies in rapid succession, i.e. the first observation of a polyoestrous pattern in molossids.

This work could not have been brought to completion on time without the contribution of Ms. Toni Foster who spent long hours expertly typing drafts and final copy of the manuscript. I also thank Dr Beth Richardson whose careful editorial scrutiny and cheerful professional advice and support made the task worthwhile. The drawing of the male reproductive tract of Desmodus was beautifully rendered by Paula E. DiSanto.

\section{References}

Baker, J.R. \& Baker, Z. (1936) The seasons in a tropical rainforest (New Hebrides): Part II. Fruit bats (Pteropidae). J. Linn. Soc. Lond. 40, 123-141.

Baker, J.R. \& Bird, T.F. (1936) The seasons in a tropical rainforest (New Hebrides): Part IV. Insectivorous bats. J. Linn. Soc. Lond. 40, 143-161.

Basra, K.A.R. (1967) Notes on the biology of the tomb bat, Taphozous nudiventris magnus v. Wellstein 1913, in Iraq. Saugetierk. Mitt. 16, 21-26.

Beck, A.J. \& Lim, B.L. (1973) Reproductive biology of Eonycteris spelaea, Dobson (Megachiroptera) in West Malaysia. Acta trop. 30, 251-260.

Bradshaw, G.V.R. (1961) Le cycle de reproduction de Macrotus californicus (Chiroptera, Phyllostomatidae). Mammalia 25, 117-119.
Bradshaw, G.V.R. (1962) Reproductive cycle of the California leaf-nosed bat, (Macrotus californicus). Science, N.Y. 136, 645-646.

Braestrup, F.W. (1933) On the taxonomic value of the subgenus Lophomops (Nyctinomine Bats), with remarks on the breeding time of African bats. Ann. Mag. nat. Hist. (Ser. 10) 11, 269-274.

Broadbooks, H.E. (1961) The funnel-eared bat in Sonora. J. Mammal. 42, 403.

Brosset, A. (1968) La permutation du cycle sexual saisonnier chez le chiroptère Hipposideros caffer au voisinage de l'equateur. Biol. Gabonica 4, 325331.

Carter, D.C. (1970) Classification of bats. In About Bats, pp. 233-246. Eds B. H. Slaughter \& D. W. 
Walton. Southern Methodist University Press, Dallas.

Douglas, A.M. (1967) The natural history of the ghost bat, Macroderma gigas (Microchiroptera, Megadermatidae), in Western Australia. West. Aust. Nat. 10, 125-138.

Dwyer, P.D. (1970) Latitude and breeding season in a polyoestrous species of Myotis. J. Mammal. 51, 405410 .

Fayenuwo, J.O. \& Halstead, L.B. (1974) Breeding cycle of straw-colored fruit bat, Eidolon helvum, at Ile-Ife, Nigeria. J. Mammal. 55, 453-454.

Fleming, T.H., Hooper, E.T. \& Wilson, D.E. (1972) Three Central American bat communities: structure, reproductive cycles, and movement patterns. Ecology 53, 555-569.

Gopalakrishna, A. (1948) Studies on the embryology of microchiroptera. Part II. Reproduction in the male vespertilionid bat Scotophilus wroughtoni (Thomas). Proc. Indian Acad. Sci. B 27, 137-151.

Gopalakrishna, A. (1955) Observations on the breeding habits and ovarian cycle in the Indian sheath-tailed bat, Taphozous longimanus (Hardwicke). Proc. natn. Inst. Sci. India 21, 29-41.

Gopalakrishna, A. (1969) Unusual persistence of the corpus luteum in the Indian fruit-bat Rousettus leschenaulti (Desmaret). Curr. Sci. 38, 388-389.

Gopalakrishna, A. \& Madhavan, A. (1971) Survival of spermatozoa in the female genital tract of the Indian vespertilionid bat, Pipistrellus ceylonicus chrysothrix (Wroughton), Proc. Indian Acad. Sci. B 73, 43-49.

Groome, M.A. (1940) The seasonal modification of the interstitial tissue of the testis in the fruit bat (Pteropus). Proc. zool. Soc. Lond. 110, 37-42.

Hall, E.R. \& Dalquest, W.W. (1963) The mammals of Veracruz. Univ. Kans. Publs. Mus. nat. Hist. 14, $165-362$.

Harrison, D.L. (1958) A note on successive pregnancies in an African bat (Tadarida pumila websteri Dollman). Mammalia 22, 592-594.

Jones, C. (1972) Comparative ecology of three pteropid bats in Rio Muni, West Africa. J. Zool., Lond. 167, 353-370.

Kingdon, J. (1974) Bats. In East African Mammals: an Atlas of Evolution in Africa, Vol. II, Part A, pp. 110-341. Academic Press, London.

Kitchener, D.J. (1973) Reproduction in the common sheath-tailed bat, Taphozous georgianus (Thomas) (Microchiroptera: Emballonuridae), in Western Australia. A ust. J. Zool. 21, 375-389.

Koopman, K.F. \& Jones, J.K., Jr. (1970) Classification of bats. In About Bats, pp. 22-28. Eds B. H. Slaughter \& D. W. Walton. Southern Methodist University Press, Dallas.

Krutzsch, P.H., Watson, R.H. \& Lox, C.D. (1976) Reproductive biology of the male leaf-nosed bat, Macrotus waterhousii in southwestern United States. Anat. Rec. 184, 611-636.

Kumar, T.C.A. (1965) Reproduction in the rat-tailed bat Rhinopoma kinneari. J. Zool., Lond. 147, 147-155.

Lang, H. \& Chapin, J.P. (1917) The American Museum Congo Expedition collection of bats. Part II. Notes on the distribution and ecology of Central African Chiroptera. Bull. Am. Mus. Nat. Hist. 37, 479-496.

Lim, B.L. (1970) Food habits and breeding cycle of the
Malaysian fruit-eating bat, Cynopterus brachyotis. J. Mammal. 51, 174-177.

Marshall, A.J. (1947) The breeding cycle of an equatorial bat (Pteropus giganteus of Ceylon). Proc. Linn. Soc. Lond. 159, 103-111.

Marshall, A.J. \& Corbet, P.S. (1959) The breeding biology of equatorial vertebrates: Reproduction of the bat Chaerephon hindei Thomas at latitude $0^{\circ} 26^{\prime}$ N. Proc. zool. Soc. Lond. 132, 607-616.

Matthews, L.H. (1939) Post-partum oestrus in a bat. Nature, Lond. 143, 643.

Matthews, L.H. (1941) Notes on the genitalia and reproduction of some African bats. Proc. zool. Soc. Lond. 111, 289-346.

Medway, Lord (1971) Observations of social and reproductive biology of the bent-winged bat Miniopterus australis in northern Borneo. J. Zool, Lond. 165, 261-273.

Medway, Lord (1972) Reproductive cycles of the flatheaded bats Tylonycteris pachypus and $T$. robustula (Chiroptera: Vespertilioninae) in a humid equatorial environment. Zool. J. Linn. Soc. 51, 33-61.

Menzies, J.I. (1973) A study of leaf-nosed bats (Hipposideros caffer and Rhinolophus landeri) in a cave in northern Nigeria. J. Mammal. 54, 930-945.

Moghe, M.A. (1952) Development and placentation of the Indian fruit bat, Pteropus giganteus giganteus (Brünnich). Proc. zool. Soc. Lond. 121, 703-721.

Mokkapati, S. \& Dominic, C.J. (1976) Sites of production of fructose and citric acid in the accessory reproductive glands of three species of male chiropterans. Biol. Reprod. 14, 627-629.

Murthy, K.V.R. (1969) Histophysiology of the penis in the Indian sheath-tailed bat Taphozous longimanus (Hardwicke), with notes on the morphology of the internal genitalia. J. zool. Soc. India 21, 149-159.

Mutere, F.A. (1965) Delayed implantation in an equatorial fruit bat. Nature, Lond. 207, 780.

Mutere, F.A. (1967) The breeding biology of equatorial vertebrates: reproduction in the fruit bat, Eidolon helvum, at latitude $0^{\circ} 20^{\prime}$ N. J. Zool, Lond. 153, 153-161.

Mutere, F.A. (1968a) The breeding biology of the fruit bat Rousettus aegyptiacus E. Geoffroy living at $0^{\circ} 22$ 'S. Acta trop. 25, 97-108.

Mutere, F.A. (1968b) Breeding cycles in tropical bats in Uganda. J. appl. Ecol. 5, 8-9.

Mutere, F.A. (1970) The breeding biology of equatorial vertebrates: reproduction in the insectivorous bat, Hipposideros caffer, living at $0^{\circ} 27^{\prime}$ N. Bijdr. Dierk. 40, 56-58.

Mutere, F.A. (1973a) A comparative study of reproduction in two populations of the insectivorous bats, Otomops martiensseni, at latitudes $1^{\circ} 5^{\prime} \mathrm{S}$. and $2^{\circ} 30^{\prime}$ S. J. Zool., Lond. 171, 79-92.

Mutere, F.A. (1973b) Reproduction in two species of equatorial free-tailed bats (Molossidae). E. Afr. Wildl. J. 11, 271-280.

Myers, P. (1977) Patterns of reproduction of four species of vespertilionid bats in Paraguay. Univ. Calif. Publs Zool. 107, 1-41.

Nelson, J.E. (1965) Behavior of Australian Pteropodidae (Megachiroptera). Anim. Behav. 13, 544-557.

Okia, N.O. (1974a) Breeding in Franquet's bat, Epomops 
franqueti (Tomes), in Uganda. J. Mammal. 55, 462465.

Okia, N.O. (1974b) The breeding pattern of the eastern epauletted bat, Epomophorus anurus Heuglin, in Uganda. J. Reprod. Fert. 37, 27-31.

Racey, P.A. \& Tam, W.H. (1974) Reproduction in male Pipistrellus pipistrellus (Mammalia: Chiroptera). $J$. Zool., Lond. 172, 101-122.

Racey, P.A., Suzuki, F. \& Medway, Lord (1975) The relationship between stored spermatozoa and the oviductal epithelium in bats of the genus Tylonycteris. In The Biology of Spermatozoa, pp. 123-133. Eds E. S. E. Hafez \& C. G. Thibault. Karger, Basel.

Rajalakshmi, M. \& Prasad, M.R.N. (1970) Sites of formation of fructose, citric acid and sialic acid in the accessory glands of the giant fruit bat, Pteropus giganteus giganteus (Brünnich). J. Endocr. 46, 413416.

Ramakrishna, P.A. (1951) Some aspects of reproduction in the Oriental vampires, Lyroderma lyra lyra Geof. and Megaderma spasma (Linn.). J. Mysore Univ., Sec. B 11, 107-118.

Ramaswamy, K.R. (1961) Studies on the sex-cycle of the Indian vampire bat, Megaderma (Lyroderma) lyra lyra (Geoffroy) Part I. Breeding habits. Proc. natn. -Inst. Sci. India 27, 287-301.

Richardson, E.G. (1977) The biology and evolution of the reproductive cycle of Miniopterus schreibersii and Miniopterus australis (Chiroptera: Vespertilionidae). J. Zool., Lond. 183, 353-375.

Tamsitt, J.R. \& Mejia, C.A. (1962) The reproductive status of a population of the neotropical bat, Artibeus jamaicensis, at Providencia. Caribb. J. Sci. 2, 139144.

Tamsitt, J.R. \& Valdivieso, D. (1963) Reproductive cycle of the big fruit-eating bat, Artibeus lituratus Olfers. Nature, Lond. 198, 104.

Tamsitt, J.R. \& Valdivieso, D. (1965) The male reproductive cycle of the bat Artibeus lituratus. Am. Midl. Nat. 73, 150-160.

Vamburkar, S.A. (1958) The male genital tract of the Indian megachiropteran bat, Cynopterus sphinx gangeticus And. Proc. zool. Soc. Lond. 130, 57-77.

Verschuren, J. (1957) Exploratie van het Nationaal Garamba Park; Ecologie, Biologie et Systématique des Cheiroptères. Fasc. 7, 473 pp. Institut des Parcs Nationaux du Congo Belge, Bruxelles.

Wilson, D.E. (1973) Reproduction in neotropical bats. Period. Biol. 75, 215-217.

Wilson, D.E. \& Findley, J.S. (1970) Reproductive cycle of a neotropical insectivorous bat, Myotis nigricans. Nature, Lond. 225, 1155.

Wilson, D.E. \& Findley, J.S. (1971) Spermatogenesis in some neotropical species of Myotis. J. Mammal. $\mathbf{5 2}$, $420-426$.

Wimsatt, W.A. \& Trapido, H. (1952) Reproduction and the female reproductive cycle in tropical American vampire bat, Desmodus rotundus murinus. Am. J. Anat. 91, 415-446.

Wimsatt, W.A., Krutzsch, P.H. \& Napolitano, L. (1966) Studies on sperm survival mechanisms in the female reproductive tract of hibernating bats. I. Cytology and ultrastructure of intra-uterine spermatozoa in Myotis lucifugus. Am. J. Anat. 119, 25-60. 